\title{
Corrigendum
}

\section{Corrigendum to "On the Role of Thermal Stresses during Hydraulic Stimulation of Geothermal Reservoirs"}

\author{
Gunnar Jansen and Stephen A. Miller \\ Center for Hydrogeology and Geothermics (CHYN), Laboratory of Geothermics and Geodynamics, University of Neuchâtel, \\ Neuchâtel, Switzerland \\ Correspondence should be addressed to Gunnar Jansen; gunnar.jansen@unine.ch
}

Received 28 September 2017; Accepted 2 November 2017; Published 22 November 2017

Copyright (c) 2017 Gunnar Jansen and Stephen A. Miller. This is an open access article distributed under the Creative Commons Attribution License, which permits unrestricted use, distribution, and reproduction in any medium, provided the original work is properly cited.

In the article titled "On the Role of Thermal Stresses during Hydraulic Stimulation of Geothermal Reservoirs" [1], there was an error in the Theory section, which should be corrected as follows.

In Section 2.2, equation (7) should be corrected to

$$
\begin{aligned}
\overline{\sigma_{n}} & =\frac{\sigma_{1}+\sigma_{3}-2 p_{f}+2 \sigma_{T}}{2}+\frac{\sigma_{1}-\sigma_{3}}{2} \cos (2 \theta) \\
\tau & =\frac{\sigma_{1}-\sigma_{3}}{2} \sin (2 \theta) .
\end{aligned}
$$

\section{References}

[1] G. Jansen and S. A. Miller, "On the role of thermal stresses during hydraulic stimulation of geothermal reservoirs," Geofluids, vol. 2017, Article ID 4653278, 15 pages, 2017. 

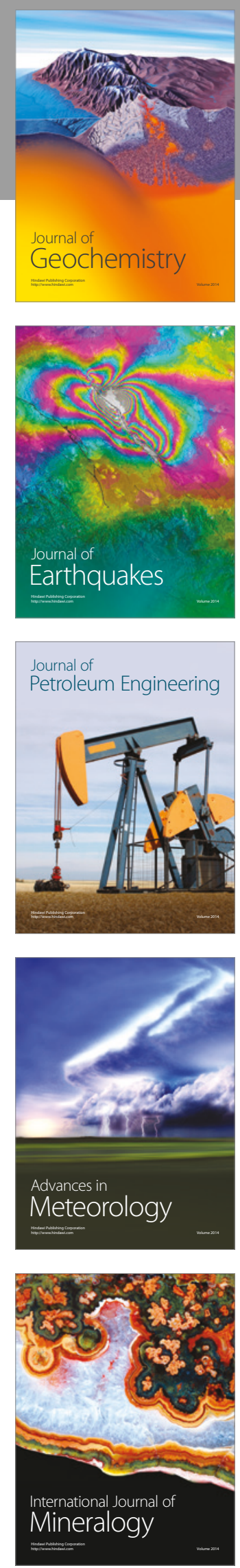
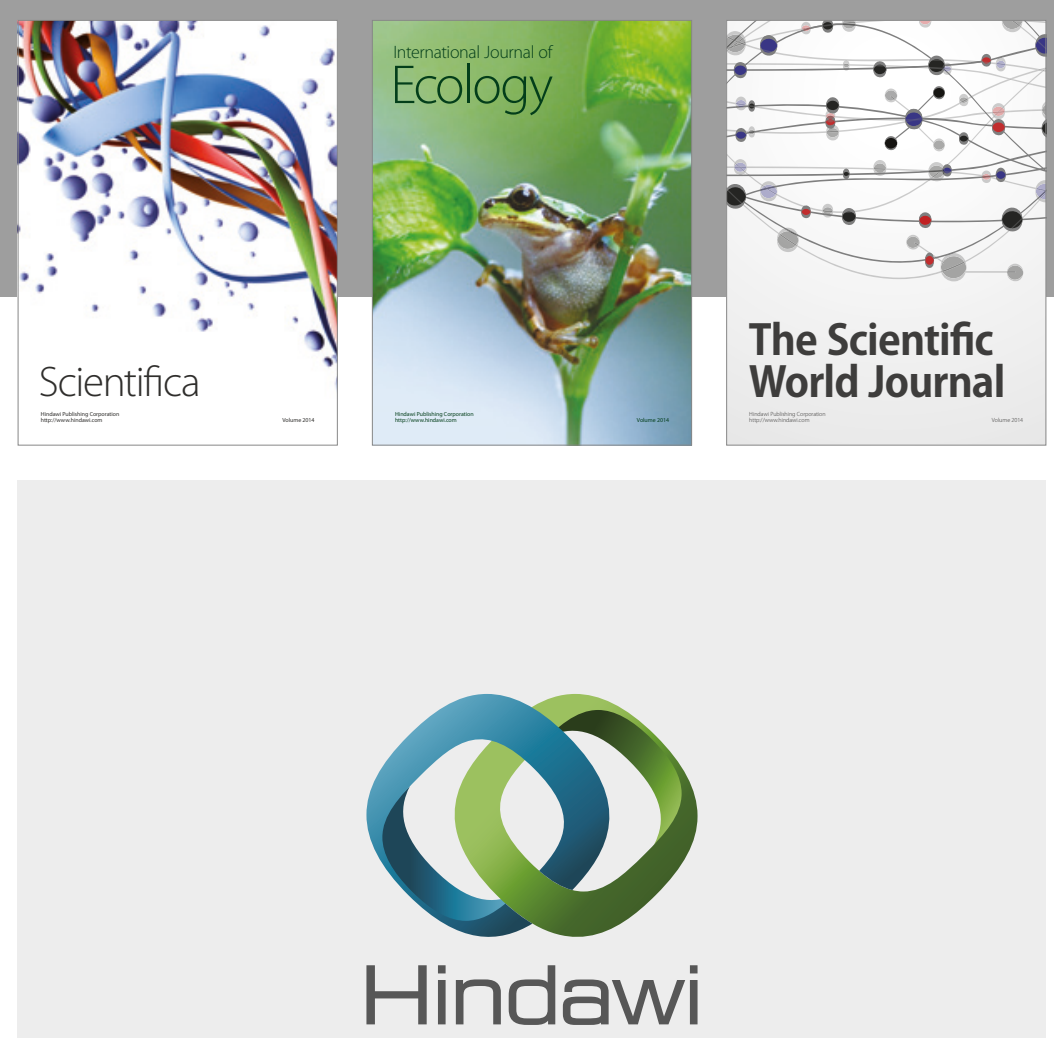

Submit your manuscripts at

https://www.hindawi.com
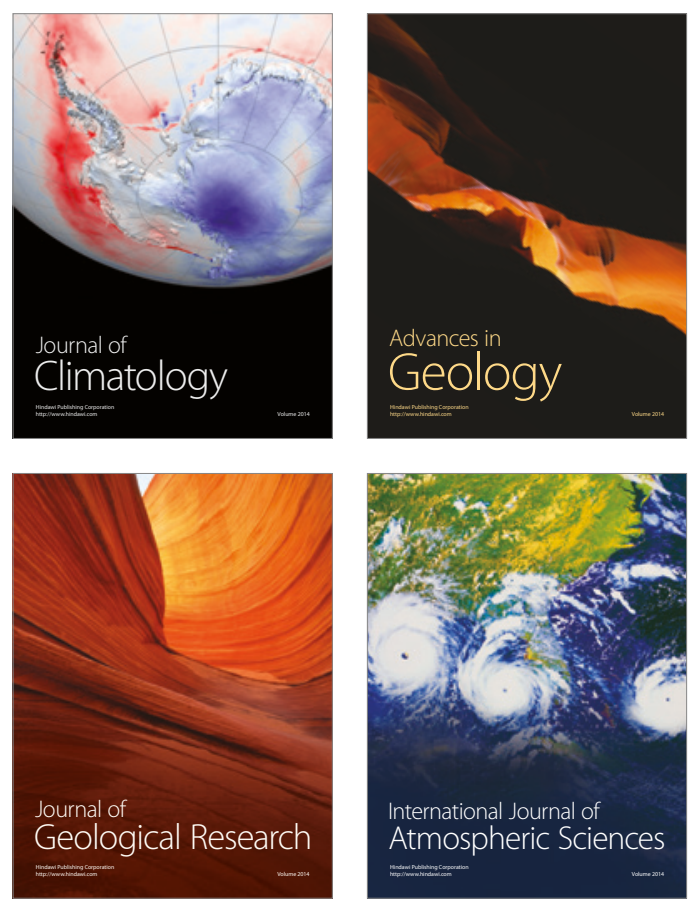

The Scientific

World Journal
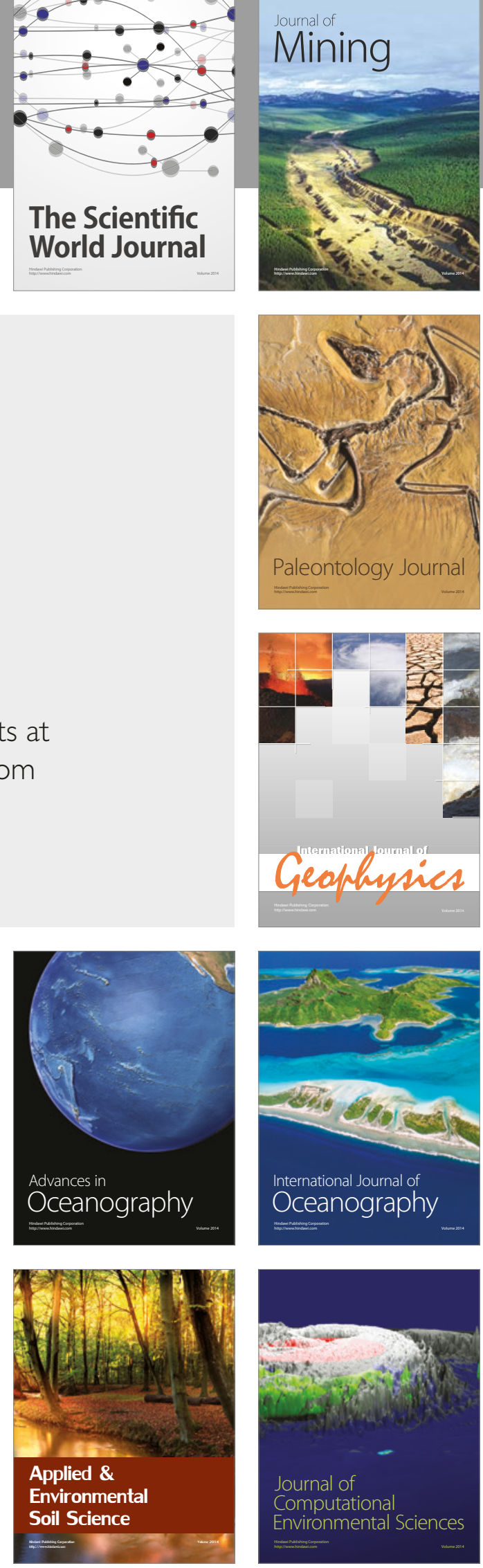